\title{
ANABOLIC EFFECT OF 17 $\alpha$ - METHYLTESTOSTERONE HORMONE ON CERTAIN BIOCHEMICAL PARAMETERS OF FISH, TILAPIA MOSSAMBICA
}

\author{
M. Nagaraju and G. Sunitha Devi \\ Department of Zoology, University College of Science, Osmania University, \\ Hyderabad-500 007, Telangana State, India.
}

\begin{abstract}
One of the major sources of animal protein for human consumption is a fisheries resource. The demand for fishhas increased in recent years due to population growth and the constant search for a healthy diet. The present study was conducted to assess an anabolic impact of an androgenic hormone, 17 $\alpha$-Methyltestosterone (MT) on Protein contentand RNA levels in certain tissues i.e. skeletal muscle, liver and gonad of fish, Tilapia mossambica. The hormone was incorporated in the feed and fed to the fish up to four weeks, in the form of three pelleted diets containing 4, 8 and $16 \mathrm{mg} \mathrm{MT} / \mathrm{kg}$ diet along with a fourth control group without hormone. The highest increment in tissue Protein content, RNA and DNA levels was observed under $16 \mathrm{mg} \mathrm{MT} / \mathrm{kg}$ diet followed by $8 \mathrm{mg} \mathrm{MT} / \mathrm{kg}$ diet and $4 \mathrm{mg} \mathrm{MT} / \mathrm{kg}$ diet in skeletal muscle, liver and gonad of fish. The more increase in Protein content, RNA and DNA levels was observed after 28 days of the $17 \alpha-$ MT oral route of administration. Hence, it is clear that the anabolic hormones such as $17 \alpha-\mathrm{MT}$ hormone play an important role in enhancing the tissue protein content for nutritional purposes. There was not much change in DNA levels.
\end{abstract}

KEYWORDS: $17 \alpha$-Methyltestosterone; Total proteins; RNA; DNA and Tilapia mossambica.

\section{INTRODUCTION}

One of the major sources of animal protein for human consumption is fisheries source. Therefore, considerable attention has been given to the production and growth of freshwater fish in aquaculture ${ }^{15}$. Aquaculture is one of the main food production sectors to deal with the high demand for food due to the human population explosion. Aquaculture, probably the fastest growing food-producing sector, now accounts for nearly 50 percent of the world's food fish ${ }^{\mathbf{1 0}}$. Aquaculture plays a leading role in the fight against food insecurity, malnutrition, and poverty globally ${ }^{24,27}$. Primary fish culture on a large scale for a commercial purpose is to obtain faster tissue growth on a low budget. The fact that anabolic promoting agents had been using it in husbandry to enhance growth rate at least cost production promoted the investigations into the use of sex hormones and their synthetic analogues in fish ${ }^{21}$. The literature on the hormonal enhancement of growth in fish has been reviewed by many authors $\mathbf{s}^{\mathbf{9} 30}$. Steroid hormones used as growth promoters in fish where they enhanced the weight gain of fish and enhanced the rate of muscle protein accretion $^{20,29}$.

$17 \alpha$-Methyltestosterone is a synthetically produced anabolic and androgenic steroid hormone; i.e. it promotes both muscle growth and therefore, the development of male sexual characters. The growth enhancement was studied in Tilapiamossambica due to anabolic effects 
among $17 \alpha$-Methyltestosterone treated and control fish ${ }^{23}$. Growth is largely protein accretion and RNA levels may be used as a measure of growth rate ${ }^{\mathbf{1 1}}$. However, the ratio of RNA to DNA is generally considered a more accurate index of growth (protein synthesis) than RNA alone since this ratio is not affected by the size of the tissue sampled for analysis ${ }^{13}$. Based on many reports, different supplementations can be added to feed in order to stimulate the growth parameters of fishes, ${ }^{2,17}$. A number of anabolic steroids both androgenic and estrogenic increase growth and food conversion efficiency when administered via food $^{14,22}$.

The present study was undertaken in order to know about the growth-promoting efficiency of the steroid hormone, $17 \alpha-\mathrm{MT}$ on Tilapia mossambica, and its impact on some biochemical Parameters as well.

\section{MATERIALS AND METHODS}

The fish, Tilapia mossambica used in the present study were procured from State fisheries culture tanks acclimatized to laboratory conditions for 10 days. Fish of uniform size of about $12 \pm 1 \mathrm{~g}$ were selected for each set of experiments. Fish were divided into four groups and kept in circular plastic troughs having a capacity of 20 litters. The fish were fed with commercial feed once a day at a rate of $2 \%$ of body weight both before and during the experimental period. The temperature was maintained at $27 \pm 1^{\circ} \mathrm{C}$ and water in the containers renewed every $24 \mathrm{~h}$.

\section{Preparation of control and steroid containing diets}

A control diet was prepared by mixing $30 \%$ of fish meal, $30 \%$ of soya bean meal, $18 \%$ of wheat bran, $13 \%$ of yellow corn, $6 \%$ of corn oil, $2 \%$ of vitamins and minerals premix, and $1 \%$ of carboxymethyl cellulose. In addition to the control diet, the other three experimental diets were prepared with the addition of 4,8 , and $16 \mathrm{mg}$ of $17 \alpha-$ $\mathrm{MT} / \mathrm{kg}$ of diet. The diets were prepared by spraying the hormone dissolved in $50 \mathrm{ml}$ of 95\% ethyl alcohol and mixed well. Glycerine was added at $0.5 \% / \mathrm{kg}$ by volume to render the harmful effect of the alcohol. The mixture of diet has been completely dried at room temperature and then sealed in an airtight black container and stored in the refrigerator until use to avoid bacterial or fungal contamination. The diets containing $17 \alpha-\mathrm{MT}$ were characterized as follows:

Oral mode: The experiments were conducted in triplicate with one control and three treatments.

Diet (1): Control diet (without 17 $\alpha$ - MT) Diet (2): $4 \mathrm{mg}$ of $17 \alpha-\mathrm{MT} / \mathrm{kg}$ of control diet.

Diet (3): $8 \mathrm{mg}$ of $17 \alpha-\mathrm{MT} / \mathrm{kg}$ of control diet.

Diet (4): $16 \mathrm{mg}$ of $17 \alpha-\mathrm{MT} / \mathrm{kg}$ of control diet.

\section{Tissue Biochemical Analysis}

The biochemical parameters such as Protein, RNA, and DNA were estimated in muscle, liver, and Gonads of the fish, Tilapia 
mossambica. These biochemical parameters were estimated by using the following methods.

$\checkmark$ Estimation of Total Protein levels by the method'.

$\checkmark$ Nucleic acids (RNA \& DNA) were extracted by the method ${ }^{25}$.

$\checkmark$ RNA(Ribose Nucleic acid) was estimated by - Orcinol method.

$\checkmark$ DNA(Deoxyribose Nucleic acid) was estimated by -Diphenylamine method.

Statistical Data:Analysed by using Student's t-test.

\section{RESULTS AND DISCUSSION}

The biochemical contents such as total proteins, RNA, and DNA levels were estimated in response to the different dosages of $17 \alpha$-Methyltestosterone for 7 days, 14 days, 21 days, and 28 days.

Proteins play an important role in the metabolism and regulation of water balance $^{12}$. It is the basic building nutrient of any growing animal and also used as an indicator of their state of health ${ }^{18}$. Protein plays a central role in cell function and cell structure and these are high molecular weight polypeptides. They are not onlyresponsible for comprising the structure of cells but areinvolved in all the aspects of cell physiology such ascatalysis, tissue repair, building, defense reactions, etc., through hormones, they regulate the metabolic aspects of the animal ${ }^{31}$. In the present study, the effect of Anabolicandrogenic steroid Methyl Testosterone (MT) to on Total Proteins, RNA (Ribose Nucleic acid), DNA (Deoxyribose Nucleic acid) in Skeletal Muscle, Liver and gonad of fish, Tilapia mossambica were studied up to four weeks $(1,2,3 \& 4$ weeks). The variations of Total Proteins, RNA, and DNA in different tissues were given in Tables (1 to 9) and Figures (1 to 6) in terms of SEM (Mean \pm SE) along with control. The results were statistically analyzed using Student's t-test, all data were presented as Mean \pm SE. $\mathrm{P}$ values were determined using the $\mathrm{t}$ statistics and denoted as NS- Not Significant, * $\mathrm{p}<0.05$; ** $\mathrm{p}<0.01$; *** $\mathrm{p}$ $<0.001$. 
Protein levels in different tissues: At the end of experimental durations, Protein levels in different tissues were significantly increased. The increase of protein levels was more at a higher dosage of $17 \alpha$ Methyltestosterone ( $17 \alpha-\mathrm{MT})$ hormone $(16 \mathrm{mg} / \mathrm{kg}$ ) and a higher duration (28 days). The order of increase was observed at higher dosage $(16 \mathrm{mg} / \mathrm{kg})$ and longer duration $(28$ days) as Muscle $(80.38 \%)$ ( $\mathrm{P}<0.001)>$ Liver $(60.18 \%)$ ( $\mathrm{P}<0.001)$ Gonad $(55.01 \%)$ $(\mathrm{P}<0.001)$ of fish.

* Protein activity in fish was significantly increased with high Methyltestosterone doses of 20 and $40 \mathrm{mg} / \mathrm{kg}^{1}$.

* Several studies are in agreement that testosterone produces muscle increasing muscle protein synthesis ${ }^{5}$. The change in protein levels may be due to the fact that androgens regulate protein synthesis by binding to cytosolic or nuclear receptors for steroids that than modulates transcription $^{28}$.

* Androgens promote male sex characteristics development as well as anabolic activity that is expressed as an increase in body weight due to increased protein biosynthesis ${ }^{\mathbf{8}, 16}$.

* The present study revealed that improvement in the quality of flesh in terms of higher protein after the fed of $17 \alpha$-Methyltestosterone up to 28 days.

Table-1. Protein content in fish Muscle after fed of different dosages of $17 \alpha$-Methyltestosterone compared to control

\begin{tabular}{|c|c|c|c|c|c|}
\hline \multirow{2}{*}{\multicolumn{2}{|c|}{ 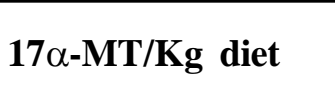 }} & \multicolumn{4}{|c|}{ Days of exposure } \\
\hline & & 7 days & 14 days & 21 days & 28 days \\
\hline Control & $\begin{array}{c}\text { Mean } \\
\text { SE }\end{array}$ & $\begin{array}{r}91.260 \\
\pm 2.252\end{array}$ & $\begin{array}{r}91.500 \\
\pm 2.003\end{array}$ & $\begin{array}{r}91.990 \\
\pm 1.678\end{array}$ & $\begin{array}{r}92.430 \\
\pm 1.957\end{array}$ \\
\hline $4 \mathrm{mg} / \mathrm{kg}$ & $\begin{array}{l}\text { Mean } \\
\text { SE } \\
\% \mathrm{~V}\end{array}$ & $\begin{array}{c}94.540^{\mathrm{NS}} \\
\pm 1.887 \\
3.60\end{array}$ & $\begin{array}{c}98 . .140 * \\
\pm 2.041 \\
7.25\end{array}$ & $\begin{array}{c}104.610 * * \\
\pm 2.188 \\
13.72\end{array}$ & $\begin{array}{c}112.580 \text { *** } \\
\pm 1.821 \\
21.79\end{array}$ \\
\hline $8 \mathrm{mg} / \mathrm{kg}$ & $\begin{array}{c}\text { Mean } \\
\text { SE } \\
\% \mathrm{~V}\end{array}$ & $\begin{array}{c}100.300 * \\
\pm 1.784 \\
9.92\end{array}$ & $\begin{array}{c}109.440 \text { ** } \\
\pm 1.940 \\
19.60\end{array}$ & $\begin{array}{c}118.600 \text { *** } \\
\pm 1.752 \\
28.93\end{array}$ & $\begin{array}{c}139.780 \text { *** } \\
\pm 1.973 \\
51.22\end{array}$ \\
\hline $16 \mathrm{mg} / \mathrm{kg}$ & $\begin{array}{c}\text { Mean } \\
\text { SE } \\
\% \mathrm{~V}\end{array}$ & $\begin{array}{c}107.950 \text { ** } \\
\pm 1.985 \\
18.29\end{array}$ & $\begin{array}{c}116.430 * * * \\
\pm 2.026 \\
27.24\end{array}$ & $\begin{array}{c}138.130 \text { *** } \\
\pm 1.893 \\
50.17\end{array}$ & $\begin{array}{c}166.730 \text { *** } \\
\pm 2.120 \\
80.38\end{array}$ \\
\hline
\end{tabular}

Each value is the Mean \pm SE of six individual observations.

Values are expressed as $\mathrm{mg}$ of protein / gram wet weight of tissue.

SE - Standard Error, \% V- Percent variation, NS: Not Significant, * $\mathrm{P}<0.05, * * \mathrm{P}<0.01$, *** $\mathrm{P}<0.001$ 
Figure-1. Protein content in fish Muscle after fed of different dosages of $17 \alpha$-Methyltestosterone compared to control (Mean \pm SE)

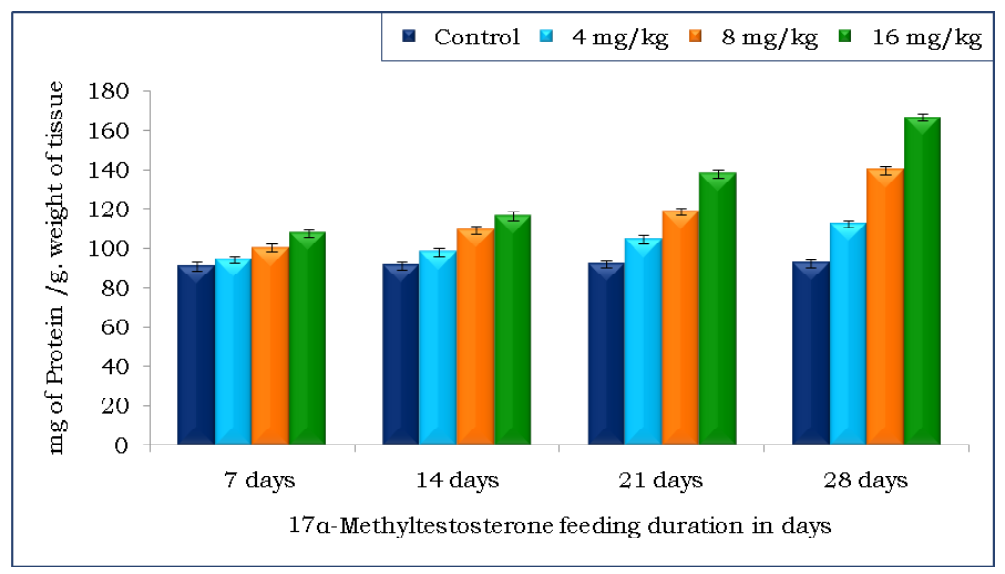

Table-2. Protein content in fish Liver after fed of different dosages of $17 \alpha$-Methyltestosterone compared to control

\begin{tabular}{|c|c|c|c|c|c|}
\hline \multirow{2}{*}{\multicolumn{2}{|c|}{$17 \alpha-M T / K g$ diet }} & \multicolumn{4}{|c|}{ Days of exposure } \\
\hline & & 7 days & 14 days & 21 days & 28 days \\
\hline Control & $\begin{array}{c}\text { Mean } \\
\text { SE }\end{array}$ & $\begin{array}{c}60.260 \\
\pm 1.742\end{array}$ & $\begin{array}{r}60.410 \\
\pm 1.635\end{array}$ & $\begin{array}{r}61.090 \\
\pm 1.467\end{array}$ & $\begin{array}{c}61.430 \\
\pm 1.592\end{array}$ \\
\hline $4 \mathrm{mg} / \mathrm{kg}$ & $\begin{array}{c}\text { Mean } \\
\text { SE } \\
\% \mathrm{~V}\end{array}$ & $\begin{array}{c}64 . .720 \mathrm{NS} \\
\pm 1.800 \\
7.40\end{array}$ & $\begin{array}{c}67.450 * \\
\pm 1.816 \\
11.66\end{array}$ & $\begin{array}{c}73.720 * * \\
\pm 2.090 \\
20.67\end{array}$ & $\begin{array}{c}77.220 * * * \\
\pm 1.966 \\
25.71\end{array}$ \\
\hline $8 \mathrm{mg} / \mathrm{kg}$ & $\begin{array}{c}\text { Mean } \\
\text { SE } \\
\% \mathrm{~V}\end{array}$ & $\begin{array}{c}70.110 * \\
\pm 1.807 \\
16.34\end{array}$ & $\begin{array}{c}77.610 * * \\
\pm 1.945 \\
28.47\end{array}$ & $\begin{array}{c}83.780 * * * \\
\pm 2.028 \\
37.13\end{array}$ & $\begin{array}{c}92.300 * * * \\
\pm 1.788 \\
50.26\end{array}$ \\
\hline $16 \mathrm{mg} / \mathrm{kg}$ & $\begin{array}{c}\text { Mean } \\
\text { SE } \\
\% \mathrm{~V}\end{array}$ & $\begin{array}{c}76.610 * * \\
\pm 1.747 \\
27.13\end{array}$ & $\begin{array}{c}83.220 * * * \\
\pm 1.687 \\
37.76\end{array}$ & $\begin{array}{c}89.110 * * * \\
\pm 1.806 \\
45.85\end{array}$ & $\begin{array}{c}98.390 * * * \\
\pm 1.935 \\
60.18\end{array}$ \\
\hline
\end{tabular}

Each value is the Mean $\pm \mathrm{SE}$ of six individual observations.

Values are expressed as $\mathrm{mg}$ of protein / gram wet weight of tissue.

SE - Standard Error, \%V- Percent variation, NS: Not Significant, * $\mathrm{P}<0.05$, ** $\mathrm{P}<0.01$, *** $\mathrm{P}<0.001$ 
Figure-2. Protein content in fish Liver after fed of different dosages of $17 \alpha$-Methyltestosterone compared to control (Mean \pm SE)

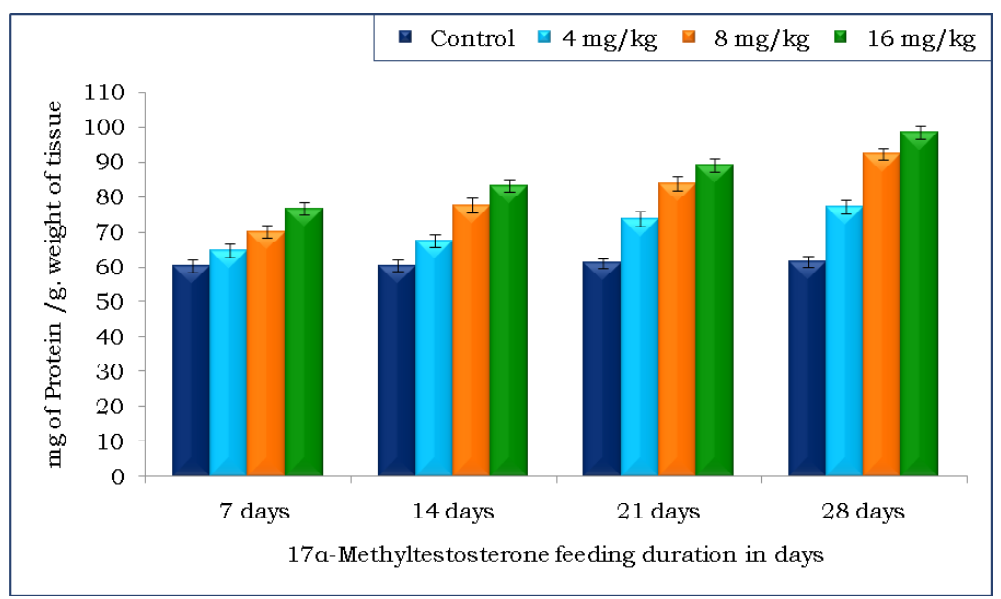

Table-3. Protein content in fish Gonad after fed of different dosages of $17 \alpha$-Methyltestosterone compared to control

\begin{tabular}{|c|c|c|c|c|c|}
\hline \multirow{2}{*}{\multicolumn{2}{|c|}{ 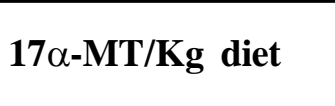 }} & \multicolumn{4}{|c|}{ Days of exposure } \\
\hline & & 7 days & 14 days & 21 days & 28 days \\
\hline Control & $\begin{array}{c}\text { Mean } \\
\text { SE }\end{array}$ & $\begin{array}{r}99.020 \\
\pm 1.858\end{array}$ & $\begin{array}{r}99.240 \\
\pm 1.706\end{array}$ & $\begin{array}{r}99.740 \\
\pm 1.617\end{array}$ & $\begin{array}{l}100.060 \\
\pm 1.751\end{array}$ \\
\hline $4 \mathrm{mg} / \mathrm{kg}$ & $\begin{array}{c}\text { Mean } \\
\text { SE } \\
\% \mathrm{~V}\end{array}$ & $\begin{array}{c}103.300^{\mathrm{NS}} \\
\pm 1.791 \\
4.32\end{array}$ & $\begin{array}{c}106.800 * \\
\pm 1.675 \\
7.61\end{array}$ & $\begin{array}{c}109.630 * * \\
\pm 1.860 \\
9.92\end{array}$ & $\begin{array}{c}117.330 * * * \\
\pm 1.829 \\
17.26\end{array}$ \\
\hline $8 \mathrm{mg} / \mathrm{kg}$ & $\begin{array}{c}\text { Mean } \\
\text { SE } \\
\% \mathrm{~V}\end{array}$ & $\begin{array}{c}108.800 * \\
\pm 1.945 \\
9.87\end{array}$ & $\begin{array}{c}117.480 * * \\
\pm 2.071 \\
18.37\end{array}$ & $\begin{array}{c}122.980 * * * \\
\pm 1.743 \\
23.30\end{array}$ & $\begin{array}{c}131.510 * * * \\
\pm 1.936 \\
31.43\end{array}$ \\
\hline $16 \mathrm{mg} / \mathrm{kg}$ & $\begin{array}{c}\text { Mean } \\
\text { SE } \\
\% \mathrm{~V}\end{array}$ & $\begin{array}{c}118.160 * * \\
\pm 1.896 \\
19.33\end{array}$ & $\begin{array}{c}129.070 * * * \\
\pm 1.981 \\
30.06\end{array}$ & $\begin{array}{c}142.310 * * * \\
\pm 2.073 \\
42.68\end{array}$ & $\begin{array}{c}155.100 \text { *** } \\
\pm 1.784 \\
55.01\end{array}$ \\
\hline
\end{tabular}

Each value is the Mean $\pm \mathrm{SE}$ of six individual observations.

Values are expressed as $\mathrm{mg}$ of protein / gram wet weight of tissue.

SE - Standard Error, \%V- Percent variation, NS: Not Significant, * $\mathrm{P}<0.05, * * \mathrm{P}<0.01, * * * \mathrm{P}<0.001$ 
Figure-3. Protein content in fish Gonad after fed of different dosages of $17 \alpha$-Methyltestosterone compared to control (Mean \pm SE)

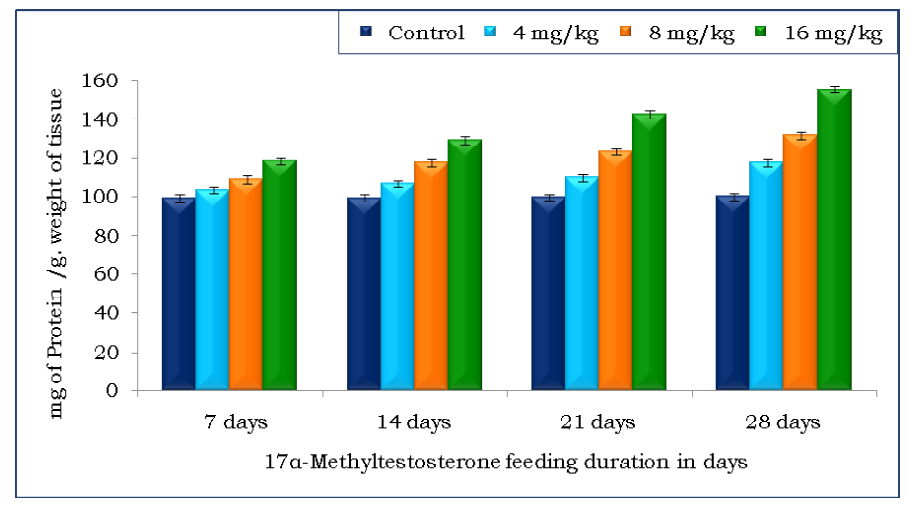

\section{RNA levels in different tissues}

The Nucleic Acids play a decisive role in regulating cellular activities so that they serve as important biomarkers of the metabolic potential of cells in the organism ${ }^{4}$. Ribonucleic acid or RNA is a nucleic acid polymer consisting of nucleotide monomers that play several important roles in the processes that translate genetic information from deoxyribonucleic acid (DNA) into protein products; RNA acts as a messenger between DNA and therefore the protein synthesis complexes referred to as ribosomes form vital portions of ribosomes, and acts as an important carrier molecule for amino acids to be utilized in protein synthesis. RNA is a polymer with a ribose and phosphate backbone and four different bases: adenine, guanine, cytosine, and uracil ${ }^{32}$.

In the present investigation, the Nucleic acid levels (RNA) in different tissues like Muscle, Liver, and Gonad were observed under different dosages of $17 \alpha-\mathrm{MT}$. There was a significant increase in RNA levels in all tissues at all durations and in all different concentrations were observed. The order of increase in different tissues when exposed to different concentrations was observed as Gonad $(73.23 \%, \mathrm{p}<0.001)>$ Liver $(61.63 \%, \mathrm{p}<0.001)>$ Muscle $(58.52 \%, \mathrm{p}$ $<0.001)$ of fish compared to control. An increase of RNA amount was more at a higher concentration of $17 \alpha-\mathrm{MT}(16 \mathrm{mg})$ and a higher duration (28 days). Similar results were observed that the RNA arising in larger quantity is instrumental in turning out a greater quantity of protein ${ }^{26}$.

A raise in RNA content in the tissues of Tilapia mossambica would reflect the induced synthesis of nucleic acids. This clearly evidences that the protein synthesis machinery of the fishes has been adversely affected. The same result showed that increased growth is represented by an increase in protein and with constant DNA and increased $\mathrm{RNA}^{7}$. 
Table-4. RNA content in fish Muscle after fed of different dosages of $17 \alpha$-Methyltestosterone compared to control

\begin{tabular}{|c|c|c|c|c|c|}
\hline \multirow{2}{*}{\multicolumn{2}{|c|}{ 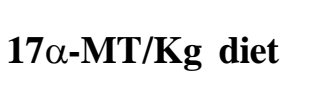 }} & \multicolumn{4}{|c|}{ Days of exposure } \\
\hline & & 7 days & 14 days & 21 days & 28 days \\
\hline Control & $\begin{array}{c}\text { Mean } \\
\text { SE }\end{array}$ & $\begin{array}{c}3.040 \\
\pm 0.090\end{array}$ & $\begin{array}{c}3.190 \\
\pm 0.081\end{array}$ & $\begin{array}{c}3.260 \\
\pm 0.097\end{array}$ & $\begin{array}{c}3.330 \\
\pm 0.087\end{array}$ \\
\hline $4 \mathrm{mg} / \mathrm{kg}$ & $\begin{array}{c}\text { Mean } \\
\text { SE } \\
\% \mathrm{~V}\end{array}$ & $\begin{array}{c}3.320 \mathrm{NS} \\
\pm 0.098 \\
9.23\end{array}$ & $\begin{array}{c}3.580 * \\
\pm 0.096 \\
12.19\end{array}$ & $\begin{array}{c}3.740 * * \\
\pm 0.102 \\
14.70\end{array}$ & $\begin{array}{c}4.0540 * * * \\
\pm 0.130 \\
21.51\end{array}$ \\
\hline $8 \mathrm{mg} / \mathrm{kg}$ & $\begin{array}{c}\text { Mean } \\
\text { SE } \\
\% \mathrm{~V}\end{array}$ & $\begin{array}{c}3.560 * \\
\pm 0.106 \\
17.19\end{array}$ & $\begin{array}{c}3 . .880 * * \\
\pm 0.125 \\
21.66\end{array}$ & $\begin{array}{c}4.260 \text { *** } \\
\pm 0.145 \\
30.53\end{array}$ & $\begin{array}{c}4.690 \text { *** } \\
\pm 0.125 \\
41.04\end{array}$ \\
\hline $16 \mathrm{mg} / \mathrm{kg}$ & $\begin{array}{c}\text { Mean } \\
\text { SE } \\
\% \mathrm{~V} \\
\end{array}$ & $\begin{array}{c}3.840 * * \\
\pm 0.104 \\
26.57\end{array}$ & $\begin{array}{c}4.310 * * * \\
\pm 0.110 \\
35.25\end{array}$ & $\begin{array}{c}4.710 \text { *** } \\
\pm 0.108 \\
44.27\end{array}$ & $\begin{array}{c}5.280 \text { *** } \\
\pm 0.100 \\
58.52\end{array}$ \\
\hline
\end{tabular}

Each value is the Mean \pm SE of six individual observations.

Values are expressed as $\mathrm{mg}$ of protein / gram wet weight of tissue.

SE - Standard Error, \%V- Percent variation, NS: Not Significant, * $\mathrm{P}<0.05$, ** $\mathrm{P}<0.01$, *** $\mathrm{P}<0.001$

Figure-4. RNA content in fish Muscle after fed of different dosages of $17 \alpha$-Methyltestosterone ompared to control (Mean \pm SE)

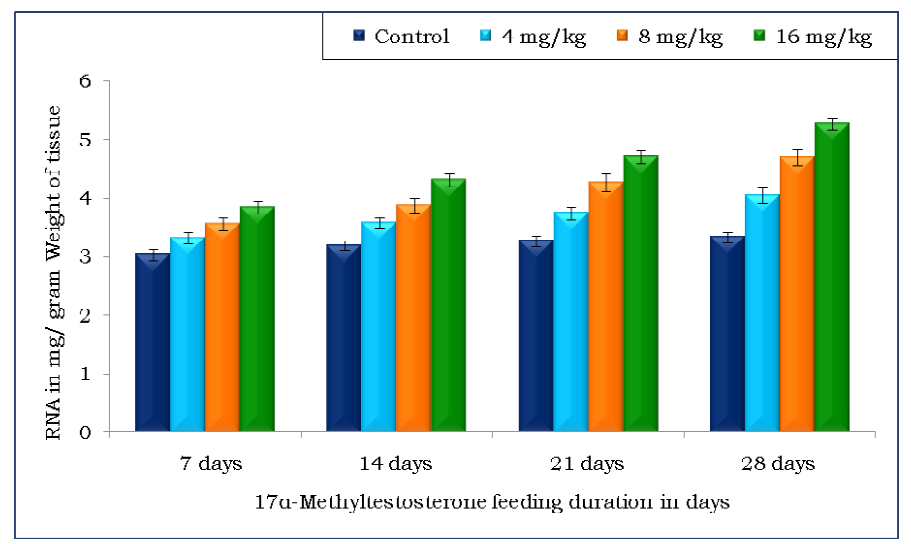

8 • J. Adv. Zool. $2020: 41(1 \& 2)$ 
Table-5. RNA content in fish Liver after fed of different dosages of $17 \alpha$-Methyltestosterone compared to control

\begin{tabular}{|c|c|c|c|c|c|}
\hline \multirow{2}{*}{\multicolumn{2}{|c|}{ 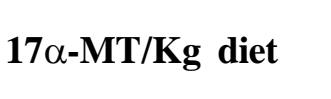 }} & \multicolumn{4}{|c|}{ Days of exposure } \\
\hline & & 7 days & 14 days & 21 days & 28 days \\
\hline Control & $\begin{array}{c}\text { Mean } \\
\text { SE }\end{array}$ & $\begin{array}{c}4.200 \\
\pm 0.166\end{array}$ & $\begin{array}{c}4.220 \\
\pm 0.162\end{array}$ & $\begin{array}{c}4.230 \\
\pm 0.184\end{array}$ & $\begin{array}{c}4.250 \\
\pm 0.159\end{array}$ \\
\hline $4 \mathrm{mg} / \mathrm{kg}$ & $\begin{array}{c}\text { Mean } \\
\text { SE } \\
\% \mathrm{~V}\end{array}$ & $\begin{array}{c}4.440 \mathrm{NS} \\
\pm 0.202 \\
5.51\end{array}$ & $\begin{array}{c}4.600 * \\
\pm 0 . .146 \\
9.06\end{array}$ & $\begin{array}{c}4.950 * \\
\pm 0.201 \\
17.35\end{array}$ & $\begin{array}{c}5.260 * * \\
\pm 0.228 \\
24.61\end{array}$ \\
\hline $8 \mathrm{mg} / \mathrm{kg}$ & $\begin{array}{c}\text { Mean } \\
\text { SE } \\
\% \mathrm{~V}\end{array}$ & $\begin{array}{c}4.710^{\mathrm{NS}} \\
\pm 0.199 \\
11.77\end{array}$ & $\begin{array}{c}5.210 * * \\
\pm 0.186 \\
23.51\end{array}$ & $\begin{array}{c}5.730 \text { *** } \\
\pm 0.193 \\
35.74\end{array}$ & $\begin{array}{c}6.330 \text { *** } \\
\pm 0.217 \\
49.95\end{array}$ \\
\hline $16 \mathrm{mg} / \mathrm{kg}$ & $\begin{array}{c}\text { Mean } \\
\text { SE } \\
\% \mathrm{~V} \\
\end{array}$ & $\begin{array}{c}4.980 * \\
\pm 0.185 \\
18.30\end{array}$ & $\begin{array}{c}5.690 * * * \\
\pm 0.164 \\
34.91 \\
\end{array}$ & $\begin{array}{c}6.070 \text { *** } \\
\pm 0.219 \\
43.90\end{array}$ & $\begin{array}{c}6.820 * * * \\
\pm 0.195 \\
61.63 \\
\end{array}$ \\
\hline
\end{tabular}

Each value is the Mean \pm SE of six individual observations.

Values are expressed as $\mathrm{mg}$ of protein / gram wet weight of tissue.

SE - Standard Error, \%V- Percent variation, NS: Not Significant, * P $<0.05$, ** $\mathrm{P}<0.01, * * * \mathrm{P}<0.001$

Figure-5. RNA content in fish Liver after fed of different dosages of $17 \alpha$-Methyltestosterone compared to control(Mean $\pm \mathrm{SE})$

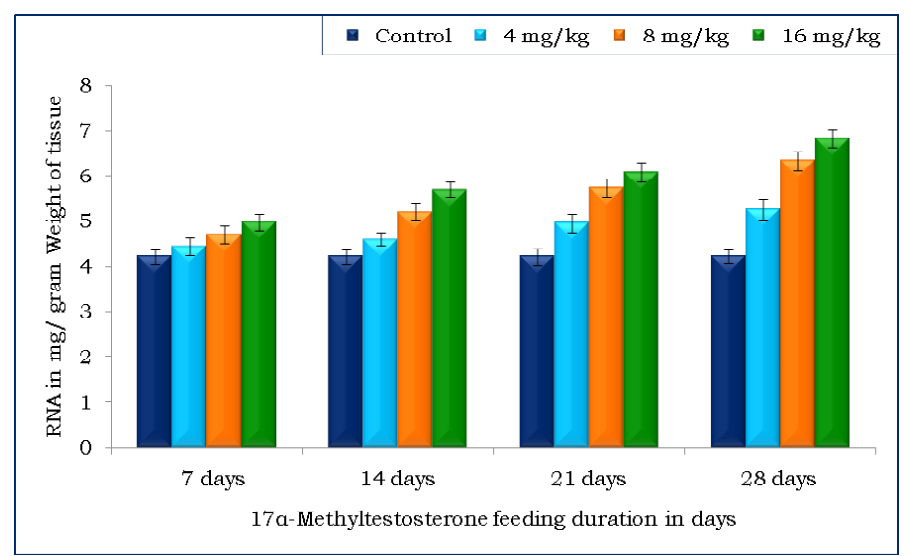


Table-6. RNA content in fish Gonadafter fed of different dosages of $17 \alpha$-Methyltestosterone compared to control

\begin{tabular}{|c|c|c|c|c|c|}
\hline \multirow{2}{*}{\multicolumn{2}{|c|}{ 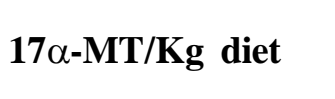 }} & \multicolumn{4}{|c|}{ Days of exposure } \\
\hline & & 7 days & 14 days & 21 days & 28 days \\
\hline Control & $\begin{array}{c}\text { Mean } \\
\text { SE }\end{array}$ & $\begin{array}{c}1.960 \\
\pm 0.076\end{array}$ & $\begin{array}{r}1.980 \\
\pm 0.089\end{array}$ & $\begin{array}{c}2.040 \\
\pm 0.085\end{array}$ & $\begin{array}{c}2.080 \\
\pm 0.078\end{array}$ \\
\hline $4 \mathrm{mg} / \mathrm{kg}$ & $\begin{array}{c}\text { Mean } \\
\text { SE } \\
\% \mathrm{~V}\end{array}$ & $\begin{array}{c}2.170 * \\
\pm 0.045 \\
10.80\end{array}$ & $\begin{array}{c}2.260 * \\
\pm 0.075 \\
14.29\end{array}$ & $\begin{array}{c}2.430 * \\
\pm 0.098 \\
19.20\end{array}$ & $\begin{array}{c}2.630 * * \\
\pm 0.095 \\
26.43\end{array}$ \\
\hline $8 \mathrm{mg} / \mathrm{kg}$ & $\begin{array}{c}\text { Mean } \\
\text { SE } \\
\% \mathrm{~V}\end{array}$ & $\begin{array}{c}2.380 * * \\
\pm 0.087 \\
20.99\end{array}$ & $\begin{array}{c}2.590 * * \\
\pm 0.102 \\
30.54\end{array}$ & $\begin{array}{c}2.880 * * * \\
\pm 0.095 \\
41.45\end{array}$ & $\begin{array}{c}3.160 \text { *** } \\
\pm 0.096 \\
52.29\end{array}$ \\
\hline $16 \mathrm{mg} / \mathrm{kg}$ & $\begin{array}{c}\text { Mean } \\
\text { SE } \\
\% \mathrm{~V} \\
\end{array}$ & $\begin{array}{c}2.680 \text { *** } \\
\pm 0.089 \\
36.37 \\
\end{array}$ & $\begin{array}{c}2.890 \text { *** } \\
\pm 0.118 \\
40.59\end{array}$ & $\begin{array}{c}3.170 \text { *** } \\
\pm 0.106 \\
55.65\end{array}$ & $\begin{array}{c}3.600 \text { *** } \\
\pm 0.085 \\
73.23\end{array}$ \\
\hline
\end{tabular}

Each value is the Mean \pm SE of six individual observations.

Values are expressed as $\mathrm{mg}$ of protein / gram wet weight of tissue.

SE - Standard Error, \%V- Percent variation, NS: Not Significant, * $\mathrm{P}<0.05, * * \mathrm{P}<0.01, * * * \mathrm{P}<0.001$

Figure-6. RNA content in fish Gonadafter fed of different dosages of $17 \alpha$-Methyltestosterone compared to control(Mean $\pm \mathrm{SE}$ )

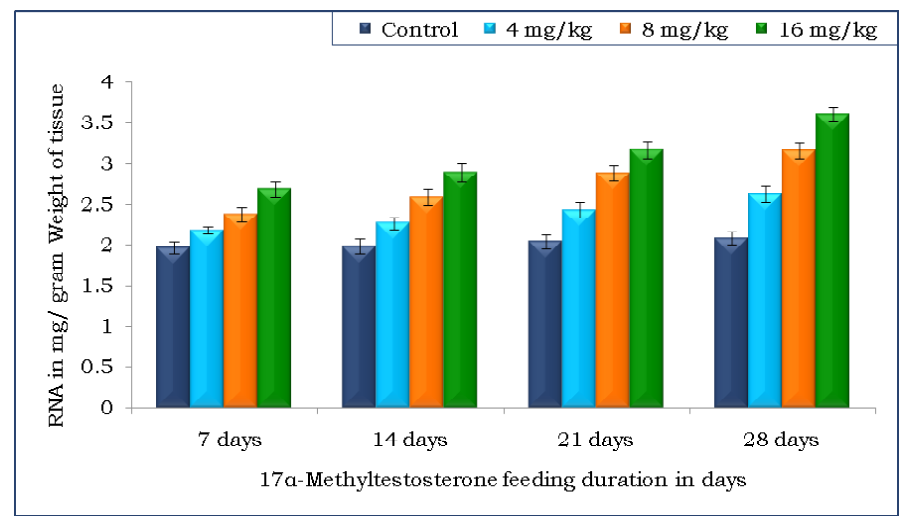


DNA levels in different tissues

Deoxyribonucleic acid (DNA) may be a molecule that carries the genetic information utilized in the expansion, development, functioning, and reproduction of all living organisms. The two DNA strands are called polynucleotides since they are composed of simpler monomer units called nucleotides ${ }^{3,19}$.

The present study revealed that DNA levels in different tissues like Muscle, Liver, and Gonads were not changed much under differentdosages of $17 \alpha-\mathrm{MT}$ but at higher concentrations $(16 \mathrm{mg} / \mathrm{kg})$ and higher duration (28 days), there was a less increase in DNA content. The quantitative changes in DNA and RNA levels in Cyprinus carpio would be due to increased activity of DNA and the inhibition of RNA polymerase function ${ }^{4}$.

Table-7. DNA content in fish Muscle after fed of different dosages of $17 \alpha$-Methyltestosterone compared to control

\begin{tabular}{|c|c|c|c|c|c|}
\hline \multirow{2}{*}{\multicolumn{2}{|c|}{ 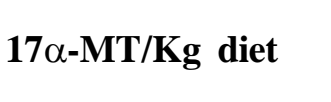 }} & \multicolumn{4}{|c|}{ Days of exposure } \\
\hline & & 7 days & 14 days & 21 days & 28 days \\
\hline Control & $\begin{array}{c}\text { Mean } \\
\text { SE }\end{array}$ & $\begin{array}{c}0.851 \\
\pm 0.010\end{array}$ & $\begin{array}{c}0.855 \\
\pm 0.014\end{array}$ & $\begin{array}{c}0.867 \\
\pm 0.026\end{array}$ & $\begin{array}{c}0.872 \\
\pm 0.022\end{array}$ \\
\hline $4 \mathrm{mg} / \mathrm{kg}$ & $\begin{array}{c}\text { Mean } \\
\text { SE }\end{array}$ & $\begin{array}{l}0.808^{\mathrm{NS}} \\
\pm 0.015\end{array}$ & $\begin{array}{l}0.839 \mathrm{NS} \\
\pm 0.023\end{array}$ & $\begin{array}{l}0.854 \mathrm{NS} \\
\pm 0.032\end{array}$ & $\begin{array}{l}0.848 \mathrm{NS} \\
\pm 0.046\end{array}$ \\
\hline $8 \mathrm{mg} / \mathrm{kg}$ & $\begin{array}{c}\text { Mean } \\
\text { SE }\end{array}$ & $\begin{array}{l}0.843^{\mathrm{NS}} \\
\pm 0.029\end{array}$ & $\begin{array}{l}0.844 \mathrm{NS} \\
\pm 0.018\end{array}$ & $\begin{array}{l}0.865 \mathrm{NS} \\
\pm 0.042\end{array}$ & $\begin{array}{l}0.894 * \\
\pm 0.034\end{array}$ \\
\hline $16 \mathrm{mg} / \mathrm{kg}$ & $\begin{array}{c}\text { Mean } \\
\text { SE }\end{array}$ & $\begin{array}{l}0.837^{\mathrm{NS}} \\
\pm 0.013\end{array}$ & $\begin{array}{l}0.859^{\mathrm{NS}} \\
\pm 0.025\end{array}$ & $\begin{array}{l}0.895^{\mathrm{NS}} \\
\pm 0.027\end{array}$ & $\begin{array}{l}0.907 * \\
\pm 0.029\end{array}$ \\
\hline
\end{tabular}

Each value is the Mean \pm SE of six individual observations.

Values are expressed as $\mathrm{mg}$ of protein / gram wet weight of tissue.

SE - Standard Error, \%V- Percent variation, NS: Not Significant, * $\mathrm{P}<0.05$, 
Table-8. DNA content in fish Liver after fed of different dosages of $17 \alpha$-Methyltestosterone compared to control.

\begin{tabular}{|c|c|c|c|c|c|}
\hline \multirow{2}{*}{\multicolumn{2}{|c|}{ 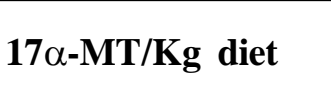 }} & \multicolumn{4}{|c|}{ Days of exposure } \\
\hline & & 7 days & 14 days & 21 days & 28 days \\
\hline Control & $\begin{array}{c}\text { Mean } \\
\text { SE }\end{array}$ & $\begin{array}{c}0.418 \\
\pm 0.011\end{array}$ & $\begin{array}{c}0.403 \\
\pm 0.022\end{array}$ & $\begin{array}{r}0.415 \\
\pm 0.027\end{array}$ & $\begin{array}{c}0.422 \\
\pm 0.013\end{array}$ \\
\hline $4 \mathrm{mg} / \mathrm{kg}$ & $\begin{array}{c}\text { Mean } \\
\text { SE }\end{array}$ & $\begin{array}{l}0.421 \mathrm{NS} \\
\pm 0.015\end{array}$ & $\begin{array}{l}0.462 \mathrm{NS} \\
\pm 0.017\end{array}$ & $\begin{array}{l}0.424 \mathrm{NS} \\
\pm 0.012\end{array}$ & $\begin{array}{l}0.441 \mathrm{NS} \\
\pm 0.019\end{array}$ \\
\hline $8 \mathrm{mg} / \mathrm{kg}$ & $\begin{array}{c}\text { Mean } \\
\text { SE }\end{array}$ & $\begin{array}{l}0.433 \mathrm{NS} \\
\pm 0.012\end{array}$ & $\begin{array}{l}0.444 \mathrm{NS} \\
\pm 0.014\end{array}$ & $\begin{array}{l}0.472 \mathrm{NS} \\
\pm 0.018\end{array}$ & $\begin{array}{l}0.464 * \\
\pm 0.022\end{array}$ \\
\hline $16 \mathrm{mg} / \mathrm{kg}$ & $\begin{array}{c}\text { Mean } \\
\text { SE }\end{array}$ & $\begin{array}{l}0.404 \mathrm{NS} \\
\pm 0.019\end{array}$ & $\begin{array}{l}0.459 \mathrm{NS} \\
\pm 0.024\end{array}$ & $\begin{array}{l}0.433 * \\
\pm 0.020\end{array}$ & $\begin{array}{l}0.489 * \\
\pm 0.027\end{array}$ \\
\hline
\end{tabular}

Each value is the Mean \pm SE of six individual observations.

Values are expressed as $\mathrm{mg}$ of protein / gram wet weight of tissue.

SE - Standard Error, \%V- Percent variation, NS: Not Significant, $* \mathrm{P}<0.05$,

Table-9. DNA content in fish Gonadafter fed of different dosages of $17 \alpha$-Methyltestosterone compared to control

\begin{tabular}{|c|c|c|c|c|c|}
\hline \multirow{2}{*}{\multicolumn{2}{|c|}{ 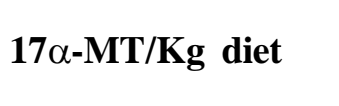 }} & \multicolumn{4}{|c|}{ Days of exposure } \\
\hline & & 7 days & 14 days & 21 days & 28 days \\
\hline Control & $\begin{array}{c}\text { Mean } \\
\text { SE }\end{array}$ & $\begin{array}{c}1.011 \\
\pm 0.029\end{array}$ & $\begin{array}{r}1.014 \\
\pm 0.043\end{array}$ & $\begin{array}{c}1.012 \\
\pm 0.018\end{array}$ & $\begin{array}{r}1.010 \\
\pm 0.027\end{array}$ \\
\hline $4 \mathrm{mg} / \mathrm{kg}$ & $\begin{array}{c}\text { Mean } \\
\text { SE }\end{array}$ & $\begin{array}{l}1.012 \mathrm{NS} \\
\pm 0.038\end{array}$ & $\begin{array}{l}1.011 \mathrm{NS} \\
\pm 0.027\end{array}$ & $\begin{array}{l}1.009 \mathrm{NS} \\
\pm 0.039\end{array}$ & $\begin{array}{l}1.012 \mathrm{NS} \\
\pm 0.046\end{array}$ \\
\hline $8 \mathrm{mg} / \mathrm{kg}$ & $\begin{array}{c}\text { Mean } \\
\text { SE }\end{array}$ & $\begin{array}{l}1.024 \mathrm{NS} \\
\pm 0.039\end{array}$ & $\begin{array}{l}1.028^{\mathrm{NS}} \\
\pm 0.041\end{array}$ & $\begin{array}{l}1.015^{\mathrm{NS}} \\
\pm 0.053\end{array}$ & $\begin{array}{l}1.037 \mathrm{NS} \\
\pm 0.034\end{array}$ \\
\hline $16 \mathrm{mg} / \mathrm{kg}$ & $\begin{array}{c}\text { Mean } \\
\text { SE }\end{array}$ & $\begin{array}{l}1.017 \mathrm{NS} \\
\pm 0.024\end{array}$ & $\begin{array}{l}1.045 \mathrm{NS} \\
\pm 0.029\end{array}$ & $\begin{array}{l}1.032 * \\
\pm 0.045\end{array}$ & $\begin{array}{l}1.049 * \\
\pm 0.052\end{array}$ \\
\hline
\end{tabular}

Each value is the Mean $\pm \mathrm{SE}$ of six individual observations.

Values are expressed as $\mathrm{mg}$ of protein / gram wet weight of tissue.

SE - Standard Error, \%V- Percent variation, NS: Not Significant, * $\mathrm{P}<0.05$, 


\section{CONCLUSION}

Based on the results obtained from the present study, it was concluded that $17 \alpha$ MT induced Protein synthesis in different tissues of Tilapia mossambica. Hence, it is clear that the anabolic hormones such as 17á-MT hormone play an important role in enhancing the tissue protein content in fish for the nutritional purpose of Man.

\section{REFERENCES}

1. Ahmad, M.H., A.M.E. Shalaby, Y.A.E. Khattab and M. Abdel-Tawwab, 2002. Effects of $17 \alpha$ -methyltestosterone on growth performance and some physiological changes of Nile tilapia fingerlings (Oreochromis niloticus L.). Egypt. J. Aquat. Biol. Fish., 4(4):295-311.

2. Ajiboye, O.O., 2015. The efficacy of the steroid hormone, $17 \alpha$-methyltestosterone and semi flow-through culture system as growth promoters and reproduction inhibitors of Nile tilapia (O. niloticus) fed two feed type. Int. J. Aquacult, 5:1-8.

3. Alberts, B., D. Bray, K. Hopkins, A. Johnson, J. Lewis, M. Raff, K. Roberts and P. Walter, 2014. Energy generation in mitochondria and chloroplasts. Essential Cell Biology: An Introduction to the Molecular Biology of the Cell, pp. 407-445.

4. Bhanu, A.P., 2016. Fate of Nucleic Acids in the Tissues of Cyprinis carpio under the Toxicity of Heavy Metals. International Journal of Pure and Applied Bioscience, 4(3): 197-200.

5. Bhasin, S., L. Woodhouse and T.W. Storer, 2001. Proof of the effect of testosterone on skeletal muscle. Journal of Endocrinology, 170:2738.

6. Bradford MM., 1976. A rapid and sensitive method for the quantitation of microgram quantities of protein Utilizing the principle of protein-dye binding. Anal Biochem, 72:248-254.
7. Dagg, M.J. and J.C. Littlepage, 1972. Relations between growth rate and RNA, DNA, protein and dry weight in Artemia salina and Euchaeta elongata; Mar. Bioi. 18:162-170.

8. Desprez, D., E. Géraz, M.C. Hoareau, C. Mélard, and P. Bosc, et al., 2003. Production of a high percentage of male offspring with natural androgen, $11 \alpha$ hydroxyandrostenedione (11 $\alpha \mathrm{OHA} 4)$ in Florida red tilapia. Aquaculture, 216:55-65.

9. Donaldson, E.M., U.H.M. Fagerlund, D.A. Higgs and J.R. McBride, 1979. Hormonal enhancement' $n 1$ of growth in fish Physiology (cds) W.S. Hoar, D.J. Randall and J.R. Brett (New York: Academic Press), 8:455-497.

10. FAO., 2011. The state of world fisheries and aquaculture, food and agriculture organization, Rome, Italy.

11. Haines, T.A., 1973. An evaluation of RNA-DNA ratio as a measure of long term growth in fish populations. J. Fish Res. Board. Can, 30:195-199.

12. Heath, A.G., 1995. Water pollution and fish physiology. CRC. Press. Inc. Boca Raton, Florida, 359.

13. Hotchkiss, R., 1955. The biological role of the deoxypentose nucleic-acids. In "The Nucleic Acids. Chemistry and Biology" (E. Chargaff and J. Davidson, Eds.). Academic Press, New York/London, 2:435- 473.

14. Jensi, A., K. Karal Marx, M. Rajkumar, R. Jeya Shakila and P. Chidambaram, 2016. Effect of $17 \alpha$-methyl testosterone on sex reversal and growth of Nile tilapia (Oreochromis niloticus L., 1758). Eco. Env. Cons. 22,14931498.

15. Juin, S.K., S. Sarkar, S. Maitra and P. Nath, 2017. Effect of fish vitellogenin on the growth of juvenile catfish, Clarias gariepinus (Burchell, 1822). Aquacult. Rep. 7:16-26.

16. Khalil, W.K.B., W.S. Hasheesh, M.A.S. Marie, H.H. Abbas and E.A. Zahran, 2011. Assessment of the impact of $17 \alpha$ methyltestosterone hormone on growth, hormone concentration, molecular and 
histopathological changes in muscle and testis of Nile tilapia; Oreochromisniloticus. Life Sci. J., 8:329-342.

17. Kumar, S., S. Behera, T.S. Nagesh, R. Gogoi and C.B. Prakash, 2016. Effect of $17 \alpha-$ Methyltestosterone on the growth performance of a fighting fish (Betta splendens). J. Exp. Zool., 19, 89-93.

18. Lea- Master, B.R., J.A. Brock, R.S. Fujioka and R.M. Akamura, 1990. Haematological and blood chemistry values for Sarotherodon melanotheron and a red hybrid Tilapia in freshwater and sea water. Comp. Biochem. Physiol., 97(A): 525-529.

19. Lodish, H., 2008. Molecular cell biology. Macmillan.

20. Lone, K.P. and A.J. Matty, 1980. Effect of feeding testosterone on the food conversion efficiency and body composition of common carp, Cyprinus carpio (L). Proc.1st. Cong. Zoo! IB: 453-467.

21. Matty, A.J. (Ed.)., 1985. Fish Endocrinology. Timber Press, Portland, Oregon. pp. 159.

22. Mc Bride, 1.R. and U.H.M. Fagerlund, 1973. The use of $17 \alpha$-methyltestosterone for promoting weight increase in juvenile coho salmon. J. Fish. Res.Bd. Canada, 30: 10991104.

23. Meyer, D.E., 1991. Growth, survival and sex ratios of Tilapia hornorum, Tilapia nilotica and their hybrid $\{T$. nilotica female $\mathrm{x} T$. hornorum male) treated with $17 \alpha-$ methyltestosterone. Diss. Abst. Int. P. B. Sci. and Eng, 57(11):75.

24. Munguti, J.M. and E.O. Ogello, 2016. Aquaculture: A promising solution for food insecurity, poverty and malnutrition in Kenya.
African Journal of Food, Agriculture, Nutrition and Development., 16(4):1133111350.

25. Munro, H.N. and A. Fleck, 1966. Recent developments in the measurement of nucleic acids in biological materials. A supplementary review. Analyst, 91(1079): 78-88.

26. Mustafa, S. and A.K. Jafri, 1977. RNA and protein contents in the flesh of teleost Channa punctatus (Bloch) during growth. Ann. Biol. Anim. Biochem. Biophys. 17: 991-995.

27. Myers, S.S., M. Smith, C.D. Golden, K.L. Seto, M.M. Dey, O.L. Chen, J.A. Gephart, B. Vaitla and E.H. Allison, 2017. Does aquaculture support the needs of nutritionally vulnerable nations? Frontiers in Marine Science; 4.

28. O’Malley, B.M. and M.J. Tsai, 1992. Molecular pathways of steroid receptor action, Biol. Reprod, 46:163-167.

29. Ostrowski, A.C. and D.L. Garling Jr., 1988. Influences of anabolic hormone treatment and dietary protein: Energy ratio on condition and muscle deposition of rainbow trout. Prog. Fish Cult, 50:136-140.

30. Pelissero, C. and J.P. Sumpter, 1992. Steroids and "steroidlike" substances in fish diets. Aquaculture, 107:283-301.

31. Sehgal, G.K. and P.K. Saxena, 1995. Effect of $17 \alpha$-Methyl testosterone on sex, composition, growth and flesh composition in common carp communis, (Cyprinus carpio L.) Indian J. Exp. Biol., 33, 169-171,

32. Sehra, S.S. and S.K. Sehra, 2012. Conceptual Translation as a part of Gene Expression. International Journal of Computers \& Technology, 3(3b): 503-505. 